\title{
MODE CHOICE ANALYSIS: THE DATA, THE MODELS AND FUTURE AHEAD
}

\author{
Minal $^{1}$, Ch. Ravi Sekhar ${ }^{2}$ \\ ${ }^{1}$ Academy of Scientific and Innovative Research (AcSIR), CSIR-Central Road Research Institute, New \\ Delhi-110025, India \\ ${ }^{2}$ Transportation Planning Division, CSIR-Central Road Research Institute, New Delhi-110025, India
}

Received 10 February 2014; accepted 7 May 2014

\begin{abstract}
Mode choice is one of the most vital stages in transportation planning process and it has direct impact on the policy making decisions. Mode choice models deals very closely with the human choice making behaviour and thus continues to attract researchers for further exploration of commuter's choice making process. The objective of this study is to carryout detailed review on various modeling methods of mode choice analysis and bottlenecks associated with the same. The factors that affect the psyche of the travelers have been discussed; further various types of data required and their method of collection has been briefed up. This paper particularly emphasizes on statistical mode choice models such as multinomial logit and probit models as well as recent advanced soft computing techniques such as Artificial Neural Network models (ANN) and Fuzzy approach model that are employed for modal split analysis. Comparative analysis were made among various modeling techniques for modeling the complex mode choice of behaviour of models carried out by various researchers in the literature and a discussion on the need of future hybrid soft computing models has been attempted.
\end{abstract}

Keywords: mode choice, data collection, logit, probit, soft-computing techniques.

\section{Introduction}

The choice of transport mode is probably one of the most important classic models in transport planning. This is because of the key role played by public transport in policy making (Ortuzar and Willumsen, 2002). Accelerated industrialization throughout the world has led to higher growth rates, increased income and high demand for mobility. Increasing number of vehicles in city causes congestion and environmental problems that lead to disrupted traffic conditions like delay, accidents which cause huge economic loss every year. Attracting the users of private modes to mass transport modes seems to be a solution but is not easily attainable given the comfort factor of mass transport facilities. To alleviate such deteriorating transportation conditions researchers have carried out studies to understand the relationship between mode choice and various factors affecting it.

Modeling of mode choice is done by means of discrete choice model (Ben-Akiva and Lerman, 1985); the different available alternatives in a discrete choice experiment are mutually exclusive and collectively exhaustive. Discrete model is based on

${ }^{2}$ Corresponding author: ravisekhar.crri@nic.in 
selecting the alternative that provides highest utility to the choice maker. Predicting the correct alternative for an individual is not always possible as many unobserved and situational variables come into play for decision making, thus the concept of random utility appeared (McFadden, 1980). Prior to 1970 s, discrete choice was used for binary choice of travel mode (Lisco, 1967), later, its use spread to multi choice set as well as in other stages of forecasting process. Since 1990, application of soft computing models such as Artificial Neural Network (ANN) models (Cantarella and De Luca, 2003), Fuzzy logic applications (Rao and Sikdar, 1999) and Genetic Algorithm (GAs) was adopted. Study on mode choice analysis benefit engineers, transportation planner and policy makers to study the existing transportation system and forecast the future needs of the proposed transportation system as we get an insight to preferences and requirements of commuters.

The philosophy behind mode choice model is to effectively manage the transport demand and be able to provide for these demands by making changes in the existing system. The objective of this paper is to provide a brief review of the state of art of the different stages and techniques of the mode choice modeling process. Since mode choice closely affects the policy decisions, it needs to be understood and practiced with great diligence. The paper aims at bringing to forefront the critical issues that needs to be dealt during mode choice analysis.

\section{Factors Affecting Mode Choice Behaviour}

Mode choice of commuters is influenced by a whole panorama of social, economic, cultural, and environmental factors like travel time, travel cost, waiting time, number and ease of transfers, comfort, etc. Over the years mode choice models have been dealing with the general range of tradeoffs individuals are willing to make among these factors (Lerman, 1975; Ben-Akiva and Lerman, 1985; Koppleman and Wen, 2000; Bhat, 2000). Zhao et al. (2002) supported the ability of transit systems with highquality services to attract more users, as well as for poor services to encourage more automobile use and classified them into the four categories named as travel mode Level of Service (LOS), accessibility, land use/urban design and transit users, socioeconomic characteristics. Later, Racca and Ratledge (2004) added characteristics of a trip as a factor that affects choice of travel mode. Researchers like Stratham and Dueker (1996) and Ye et al. (2007) have identified that tour complexity influences mode choice substantially. Residential location, neighborhood type and urban form play a prominent role in determining the favored travel mode for commute (van Wee et al., 2003; Pinjari et al., 2007; Frank et al., 2008).

The factors discussed above clearly depict that travel time is one of the highly rated factors considered in mode choice and is widely used concept in transportation analysis (Bhat and Sardesai, 2006). Recently, various researchers are considering Value of Travel Time (VOT) as an influencing parameter in choosing the mode. VOT means how much a passenger is willing to pay to avoid any increase in transport time for an average or typical mode of transport. Estimation of VOT is crucial for cost benefit analysis of transportation projects. It is also instrumental in developing congestion pricing policies. Algers et al. (1998) calculated value of time as a trade-off ratio between the in-vehicle time coefficient 
and the cost coefficient and they found that estimation of VOT is sensitive to model specification and assumptions made on the coefficients. Koppeleman and Bhat (2006) stated that VOT can serve as an important informal test for evaluating the reasonableness of the model. Researchers have found that the perceived VOT for work trips is close to the wage rate of passengers. For non-work trips this value is found to be clustered around $25 \%$ of the wage rate (Lesley, 2009).

\section{Methods of Collecting Travel Behaviour Data}

The data required for modeling is collected through surveys like household survey, workplace survey, destination survey, and intercept survey. Sampling from the data set is also a critical step and should be attempted with caution. Paper and pencil interviewing (PAPI) is an orthodox method for data collecting. It represents a process of personal interviewing where the pollster holds a printed-out questionnaire, reads the question to the respondent and fills the answers into the questionnaire. It has higher chances of error compared to Computer Assisted Interviewing (CAPI) (Kalfs, 1995). CAPI is a computer assisted data collection method for replacing paper-andpen methods of survey data collection and usually conducted at the home or business of the respondent using a portable personal computer. It allows interviewers to conduct face-to-face interview using the computer. After the interviews, the interviewers send the data to a central computer. CAPI can also include Computer Assisted Self-Interview (CASI) session where the interviewer hands over the computer to the respondent for a short period, but he/she remains available for instructions and assistance. Computer
Assisted Telephone surveys and Commuter Assisted mail surveys are increasingly being replaced by web based online (internet) surveys. Online surveys are becoming an essential research tool for a variety of research fields, including marketing, social and official statistics research. Wang et al. (2000) and Adler et al. (2002) stated from their study based on web-based travel survey that although this type of survey method is highly capable in handling complex tasks as stated preference experiments, it can be highly unreliable. Thus, the model estimated by web cannot be judged to give accurate results. Secondly, the sampling frame for internet surveys is often not available as it cannot be known that the respondents may behave totally differently to the population of interest. Recently, GPS data loggers are deployed for collecting second-bysecond location, position, and speed data (Wolf, 2004). The first passive GPS study conducted as part of a major household travel survey occurred in Austin in 1997 (Casas and Arce, 1999). In these studies, participants are provided with the GPS loggers for the duration of the study and participation is the GPS component is completely voluntary. The techniques of revealed preference and/or stated preference are used as complementary tools to elicit the preferences of the decision maker. Revealed choice data describes current observed travel patterns and costs and hence gives very accurate picture of current modal choice. However, the use of Stated Preference (SP) data had often been and still is sometimes rejected due to their unknown reliability. Morikawa (1989) proved a milestone in the acceptance of SP data and its major results were summarized in Ben-Akiva and Morikawa study (1990a). $S P$ responses cannot be used alone for forecasting actual behavior because of their unknown bias and error properties, but they 
contain very useful information on trade-offs among attributes. Ben-Akiva and Morikawa (1990b) presented the data fusion method that allows the combination of two or more complementary data sources into a single data base.

\section{Review on Mode Choice Models}

\subsection{Aggregate and Disaggregate Mode Choice Models}

Aggregate models attempt to represent the average behavior of a group of travelers instead of a single individual. Different aggregate models devised and used over past decades are a) Trend analysis where past trends were extrapolated to estimate future travel (Daganzo, 1979); b) Mathematical models like the direct demand models and sequential models are usually more difficult to implement, more time-consuming and more costly but provide more accuracy; c) Trip-end modal split, applied immediately after trip generation, and d) Trip-Interchange modal split models when modal split is applied after the trip distribution. While the former preserves the various socio-economic characteristic of the commuters the latter includes the characteristics of the journey and that of the alternative modes available to user. The aggregate transportation planning models have been severely criticized for their inflexibility and inaccuracy. These models at base attempt to represent the average behavior of a group of travelers instead of a single individual. Disaggregate models which appeared in 1980 s offer substantial advantage over its aggregate counterparts as it represents the behavior of individuals. In disaggregate approach individual choice responses as a function of the characteristics of the alternatives available and sociodemographic attributes of each individual.
It has a more causal nature and is thus more transferable to a different point in time and to a different geographic context, very well suited for proactive policy analysis. Efficiency of disaggregate approach is more than the aggregate approach in terms of model reliability per unit cost of data collection.

\subsection{Statistical Mode Choice Models}

Discriminant model considers statistical classification technique to classify dependent variable between groups and to calculate each respondent probability to get into one or another group. Zenina and Borisov (2011) used stepwise and forward stepwise discriminant analysis to model mode choice and compared the results with Multinomial Logit (MNL) model and Decision Tree (DT) models. The main problem of discriminant analysis is the selection of discriminant variables and the choice of discriminant function. Discrete choice models based on random-utility maximization are widely used in transportation applications. They have three different families of models depending upon the functional form of the error term distribution namely Logit model, Probit Model and General Extreme Value (GEV) Model. Logit model has the ability to model complex travel behaviors of any population with simple mathematical techniques and thus proves to be the most widely used tool for mode choice modeling. The mathematical framework of logit models is based on the theory of utility maximization (Ben-Akiva and Lerman, 1985). Logit models can be categorized in three types depending on whether the data or coefficients are chooserspecific or choice-specific. Multinomial logit model has chooser specific data where coefficients vary over the choices. Conditional logit model has choice-specific 
data where the coefficients are equal for all choices. Mixed logit model involves both types of data and coefficients.

\subsubsection{Multinomial Logit Models}

Multinomial Logit (MNL) model is the most basic member of the family of GEV models. There are three basic assumptions which underlie the MNL formulation. The random components of the utilities of the different alternatives are independent and identically distributed (IID) with a Type I extremevalue or Gumbel distribution. MNL model maintains homogeneity in responsiveness to attributes of alternatives across individuals. The error variance-covariance structure of the alternatives is identical across individuals. The three assumptions discussed above together lead to the simple closed-form mathematical structure of the MNL. However, these assumptions also leave the MNL model laden with the IIA property at the individual level which proves to be the greatest drawback of MNL model (Bhat, 1995). IIA property implies that any changes in the probability of a given alternative draw equally from the probabilities of all the other alternatives in the choice set (Hess, 2005). Al Ahmadi (2006) developed intercity mode choice models for Saudi Arabia using MNL and this study results indicated that in-vehicle travel time, out of pocket cost, number of family members travelling together, monthly income, travel distance, nationality of traveler, and number of cars owned by family played the major role in decision related to intercity mode choice. Mukala and Chunchu (2011) through stated preference (SP) data modeled the mode choice behavior of specific category of trip makers traveling from Guwahati to five metro cities in India. The choice set included Railways and Airways. Various forms of Standard logit models and mixed logit model were estimated. The results of this study indicate that the opening of high-speed rail services or bullet trains would definitely increase the ridership of railways provided the cost of railways is pretty reasonable as Sensitivities of time and cost are interdependent on each other. Abuhamoud et al. (2011) modeled the mode choice preference of commuters towards car use and bus use using binary logit model, in Libya. The factors affecting the choice pattern was also studied and the major outcome of the study was that gender analysis needs to be incorporated into all transport planning, so that gender impacts are studied and considered before project implementation.

\subsubsection{Nested Logit Models (NL)}

Nested Logit (NL) structure allows estimation of proportions among selected sub-modes, prior to the estimation of proportions between modes. The nested logit model have their random component identically, non-independently distributed with type I extreme value distribution allowing partial relaxation of the assumption of independence among random components of alternatives (McFadden, 1978). It has a closed form solution, is relatively simple to estimate and is more parsimonious than the multinomial probit model. The major drawbacks of NL models are first, the number of different structures in search for the best structure increases rapidly as the number of alternatives increases. Second, the actual competitive structure among alternatives may be a continuum which cannot be accurately represented by partitioning the alternatives into mutually exclusive subsets. Abdel-Aty and Abdelwahab (2001) developed mode choice models for Florida, USA. The mode choice model was estimated 
as three level Nested Logit structure. The overall model utilized full information maximum likelihood estimation. Among the significant variables that entered into model are transit access time, transit waiting time, number of transfer, in-vehicle travel time, fare and household car ownership. Khan (2007) designed Nested logit models for different trip length and trip purpose for Redland Shire. Data was collected through a Stated Preference survey in which an entirely a new virtual travel environment was created and the result of this study indicated that trip length affects the perception of alternatives to work for longer trips.

\subsubsection{Multinomial Probit Model (MNP)}

Multinomial Probit (MNP) model is the main alternative to GEV-based model structures in discrete choice analysis. The underlying assumption of Probit models is that the error terms follow a joint normal distribution with zero mean and covariance matrix with no priori restrictions on the correlation structure in the distribution. The absence of the assumption of identically distributed error terms means that taste variation and repeated choices can also be incorporated in Probit models. Thus, the cases where the utilities of some alternatives are correlated in a complex way and use of MNL models can make incorrect forecasts regarding the probabilities of mode shares when the attributes associated to one or more travelling alternatives are varied MNP model can be used. MNP model imposes a heavy computational burden due to the issue regarding identification of an appropriate covariance structure. Major disadvantage of the Probit model is the requirement to use a normal distribution for representing random taste heterogeneity, leading to significant losses in terms of flexibility and issues of interpretation in the case of counterintuitive results. Due to this complexity the transport planners generally prefer using logit models as they possess simple mathematical framework and can accurately model the travel behavior of a study area. Ghareib (1996) estimated the travel behavior for different cities of Saudi Arabia using logit and probit models and concluded that the logit models are superior to their probit counterparts in terms of their goodnessof-fit measures and tractable calibration. Dow and Endersby (2004) later supported his findings by concluding that the logit models should always be preferred over probit models and the latter should only be utilized if the travel behavior of the targeted population to be determined is observed to be complexly correlated. Bhat and Sardesai (2006) in their study pointed out that in Probit model due to increase in flexibility of error structure, several additional parameters are introduced in the covariance matrix. This generates a number of conceptual, statistical and practical problems, including difficulty in interpretation, highly non-intuitive model behavior, low precision of covariance parameter estimates, and increased difficulty in transferring models from one space-time sampling frame to another. Can (2011) used probit for tourist mode choice in Nha Trang. The major findings regarding the factors affecting the choice process are out-ofmode per kilometer, on-mode travel time per kilometer, per-kilometer travel cost to income ratio; safety, etc. affect choice decision very closely.

\subsubsection{Generalized Extreme Value (GEV) Models}

Generalized extreme value (GEV) models were developed as an important simplification of multinomial logit models 
based on the stochastic utility maximization. It is a closed form distribution that allows for various levels of correlation among the unobserved part of utility across alternatives (Hess, 2005). Random utility model is developed with independent but non-identical error terms distributed with a type I extreme value distribution. Bhat (1995) developed a Heteroscedastic Extreme Value Model of intercity mode choice. The proposed model allowed a more flexible cross-elasticity structure among alternatives than the nested logit model and was also free from the IIA assumption of MNL. Bhat (1995) made a comparative analysis among multinomial logit model, nested logit models, and heteroscedastic extreme value model and the results emphasing that heteroscedastic extreme value model shows a number of advantages over other commonly used discrete choice models. Yang et al. (2013) developed a Cross-Nested Logit model for capturing a joint choice of residential location, travel mode, and departure time using Beijing traffic data. The results were compared to Logit model and three different Nested logit models. Estimation results show the Cross-Nested Logit model outperforms the three kinds of NL model. It is also found by estimation results that decision makers will change first their departure times, then their travel modes, and finally their residential locations, when exogenous variables alter.

\subsection{Soft Computing Mode Choice Models}

Alternatively researchers have sought out to more recent soft computing techniques like Artificial Neural Network (ANN), Fuzzy Logic and hybrid models resulting from combination of ANN and Fuzzy logic. This section describes these recent models.

\subsubsection{Artificial Neural Network Models}

Cantarella and De Luca (2003) compared MNL and ANN models for mode choice modeling using disaggregate discrete choice data. Two types of neural networks were trained and the results compared to the logit model. The results revealed that ANN model adopted in this study outperformed the MNL model. Xie et al. (2003) in their mode choice studies used Decision tree (DT) and Artificial neural network (ANN). Datasets from the San Francisco Bay Area Travel Survey (BATS) 2000 were used. They compared the results obtained by these techniques with a traditional multinomial logit (MNL) model. Prediction results show that the two data mining models offer comparable but slightly better performance than the MNL model in terms of the modeling results, while the DT model demonstrates highest estimation efficiency and most explicit interpretability and the ANN model gives a superior prediction performance in most cases. Ravi Sekhar (1999) carried out a mode choice study for Delhi. In this study mode choice models based on ANN and MNL were formulated and a comparative analysis was done between both. The ANN model different models were developed based on the vehicle ownership and the choice set available to the commuters. A back propagation algorithm was used for the ANN architecture. The relative importance of input parameters was found out and Object Oriented Programming (OOP) was used to implement ANN network. ANN models outperformed the MNL models. 


\subsubsection{Fuzzy Logic Based Mode Choice Models}

Deb (1993) used Fuzzy set theory to study the Mass transit mode choice pattern for Calcutta. Different Mass transit alternatives like Bus, Car, Surface Railway, Metro and Water Transport were taken into account and fuzzy set theoretic approach was employed to select the more preferable set of alternatives. Aggregate matrix was used to compare the various alternatives included in this matrix to select the best alternative(s). An alternative was taken as superior to a second alternative if it dominated the second-alternative in more number of factors than the number of factors in which the second dominates the first. Seyedabrishami and Shafahi (2013) carried out a Trip destination and Mode choice joint model analysis by using Fuzzy set theory. The model is structured as a decision tree in which the fuzzy and non-fuzzy classification of influential variables regarding destination selection and mode choice expand the tree for Shiraz, a large city in Iran. When compared with a multinomial logit (MNL) model, the suggested models' estimates are more accurate than the traditional MNL model.

\subsubsection{Hybrid Mode Choice Models}

Fused Neuro Fuzzy (NF) architecture let ANN learning algorithms to determine the parameters of Fuzzy Inference System (FIS). Fused NF systems share data structures and knowledge representations. Yaldi et al. (2010) developed a NF model for trip distribution and mode choice analysis. The input nodes can be categorized into two types representing the socio-economic characteristics of the individuals. The activation function for nodes in both output and hidden layers was sigmoid with BackPropagation algorithm. The output was the weights assigned for each alternative mode. Rao and Sikdar (1999) carried out urban mode choice analysis by calibration of Fuzzy functions from revealed preference survey in Mumbai. They used ANN for the calibration of Fuzzy membership function. The membership function was modified by the back propagation of error. Modification was in proportion to the error signal. The model gave performance of $99.73 \%$ in calibration and $98.64 \%$ in validation suggesting accurate result.

\section{Development of Mode Choice Models}

This section discusses the different psychological and economic theory that is used in decision making process. Such theories form the basis of understanding and developing mode choice models.

\subsection{Attitude-Based Theories}

Ajzen developed the Theory of Planned Behaviour (TPB), assuming that the choice is also dependent on the individual's perception of his or her ability to execute certain behaviour (Ajzen, 1985). According to TPB, the intention behind certain behaviour is dependent on three factors namely, the attitude toward the behaviour, the social norm and the perceived behavioral control. Attitude-based theories have been criticized because it is difficult to know whether attitudes control travel mode choice or vice versa. People do not always act as they say they will. Persson et al. (1998) stated that attitudes' value for predicting actual behaviour is poor, because they are collected through interviews or questionnaires similar to Stated Preference interviews. 


\subsection{Utility Theory for Discrete Choice Model}

Utility is an indicator of value to an individual. In a discrete choice experiment, a decision-maker chooses a single alternative from a choice set of finite number of mutually exclusive alternatives where the choice set is exhaustive. An individual is visualized as selecting a mode which maximizes his or her utility (Khan, 2007). The utility of a travelling mode is defined as an attraction associated to by an individual for a specific trip. This hypothesis is known as utility maximization. This can be stated as alternative, ' $i$ ', is chosen among a set of alternatives, if and only if the utility of alternative, ' $i$ ', is greater than or equal to the utility of all alternatives, ' $j$ ', in the choice set, $C$. This can be mathematically in Eq. (1). If the utility of alternative $i$ is greater than or equal to the utility of all alternatives $j$; alternative $i$ will be preferred and chosen from the set of alternatives.

If $\boldsymbol{U}\left(\boldsymbol{X}_{\boldsymbol{i}}, \boldsymbol{S}_{\boldsymbol{t}}\right) \geq \boldsymbol{U}\left(\boldsymbol{X}_{j}, \boldsymbol{S}_{\boldsymbol{t}}\right)$

Where,

$U($ ) - mathematical utility function;

$X_{i}, X_{j}$ - vectors of attributes describing alternatives $i$ and $j$, respectively, and $S_{t}$ - Socio-economic characteristics of individual $t$.

\subsection{Deterministic and Probabilistic Choice Theory}

According to the utility maximization rule, an individual chooses the alternative with the highest utility. But there is always uncertainty involved in the individual's decision process. Utility models that assume complete rational behaviour and perfect information without taking into account the taste and preferences of individual are called deterministic utility models. There are cases when an individual chooses alternative $i$ over $j$ even when $U_{j}>U_{i}$. The primary sources of error in the use of deterministic utility functions are: First, the individual may have incomplete or incorrect information or misperceptions about the attributes of some or all of the alternatives. Second, the analyst or observer has different or incomplete information about the same attributes relative to the individuals. Third, the analyst is unlikely to know specific circumstances of the individual's travel decision, mostly the personal situations of the traveler. These errors are considered while making choice under Probabilistic Choice models or Random Utility Model in which Utility is decomposed into two components. One component of the utility function represents the portion of the utility observed by the analyst, often called the deterministic (or observable) portion of the utility. The other component is the difference between the unknown utility used by the individual and the utility estimated by the analyst, represented by $\varepsilon$ :

$U_{i t}=V_{i t}+\varepsilon_{i t}$

where $U_{i t}$ is the true utility of the alternative $i$ to the decision maker $t, V_{i t}$ is the deterministic or observable portion of the utility estimated by the analyst, and $\varepsilon_{i t}$ is the error or the portion of the utility unknown to the analyst.

\subsection{Logit Theory Model}

The mathematical framework of logit models is based on the theory of utility maximization 
(Ben-Akiva and Lerman, 1985). Logit models can be categorized in three types of logit models depending on whether the data or coefficients are chooser-specific or choice-specific. Multinomial logit model has chooser specific data where coefficients vary over the choices. Conditional logit model has choice-specific data where the coefficients are equal for all choices. Mixed logit model involves both types of data and coefficients.

Probability of an individual $i$ selecting a mode $n$, out of $M$ number of total available modes, is given in Eq. (3):

$P_{i n}=\frac{e^{V_{i n}}}{\sum_{m=1}^{M} e^{V_{i m}}}$

$V_{\text {in }}$ - utility function of mode $n$ for individual $i$;

$V_{\text {im }}$ - utility function of any mode $m$ in the choice set for an individual $i$;

$P_{\text {in }}$ - probability of individual $i$ selecting mode $n$; and

$M$ - total number of available travelling modes in the choice set for individual $i$.

The Logit model can be classified as Binary Logit model, Multinomial Logit model and Nested Logit model.

\subsection{Soft Computing Techniques}

\subsubsection{Artificial Neural Network (ANN)}

An Artificial Neural Network (ANN) is a parallel information-processing system that has certain performance characteristics similar to biological neural networks. A neural net consists of a large number of simple processing elements called neurons. Each neuron is connected to other neurons by means of directed links and each directed link has a weight associated with it. These are used to address problem that are intractable or cumbersome with traditional methods. The typical computation of Artificial Neuron is presented in Fig. 1. It can be represented mathematically, if $I_{1}, \ldots I_{i} \ldots I_{n}$ are the input values and synaptic weight values are $W_{l j}$, $\ldots W_{j}, W_{n j}$ then the summation, netj is over all the incoming neurons of the product of the incoming neuron's activation and the synaptic weight of the connection at the typical $j^{\text {th }}$ neurode expressed as $\sum I_{i} W_{i j}$. A threshold value $\theta_{1}$ is incorporated into the output. The mathematical representation of $n e t_{j}$ is given in Eq. (4).

net $_{j}=\sum_{i=1}^{n} I_{i} W_{i j}+\theta_{i}$

Where $n$ is the number of incoming neurons, $I$ is the vector of incoming neurons, $W$ is the vector of the synaptic weights and $\theta$ is node threshold, usually taken as the negative weight from the bias unit (a unit whose output is unity). The output at each neurode by considering Eq. (5):

OUTPUT $=f\left(\right.$ net $\left._{j}\right)$

Where $f\left(n e t_{j}\right)$ is activation function also called as threshold function, transfer function or squashing function used to map the input pattern of neuron to the specified output range. The most commonly used threshold functions are linear, non-linear, sigmoid, hyperbolic, tangent, etc. Most widely used function in mode choice analysis is sigmoid function. 


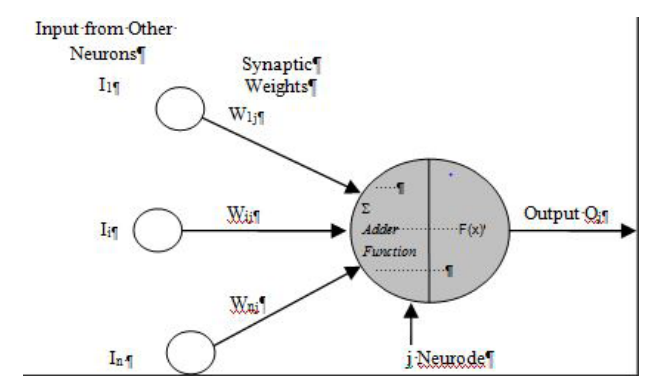

Fig. 1.

Artificial Neuron

\subsubsection{Fuzzy Logic (FL)}

Fuzzy set theory firstly introduced by Zadeh (1965) deals with propositions that can be true to a certain degree (somewhere from 0 to 1). Many of the influencing variables used as input to mode choice modeling do not follow definition of crisp set. Crisp sets allow either full membership or no membership at all whereas fuzzy sets allow partial membership. Thus, fuzzy set is an extension of a crisp set that capture vague or linguistic expression. The performance of any system controlled by Fuzzy Logic depends on the fuzzy rules, which in turn depend on the membership functions of the input variables. The most tedious and crucial part of forming the fuzzy logic is determining the membership function. In a crisp set membership of ' $x$ ' $\mu(x)$, in set $A$ is defined in Eq. (6):

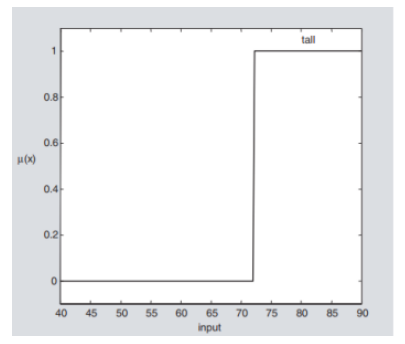

Fig. 2.

a) Crisp membership function
$\mu_{A}(x)=1$ where $x \in A$ and $\mu_{A}(x)=0$ where $x \notin A$

But fuzzy set contains certain degree of membership. The degree of membership has a value from zero to one, i.e. a value from the closed interval $[0,1]$. The greater $\mu_{A}(x)$, the greater the truth of the statement that element $x$ belongs to set $A$. (illustrated in Fig. 2).

$0 \leq \mu_{A}(x) \leq 1$, where $x \in X$.

After deciding the membership function the fuzzy rules are formed and then through Fuzzy Inference System (FIS), the input is mapped to output by using fuzzy set theory. A FIS is usually designed by considering Fuzzification, fuzzy interface through the bank of fuzzy rules and Defuzzification of the fuzzy output variables as depicted in Fig. 3.

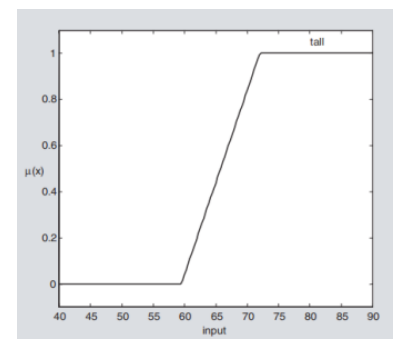

(b) Fuzzy membership function

\section{Crisp and Fuzzy Membership Function}




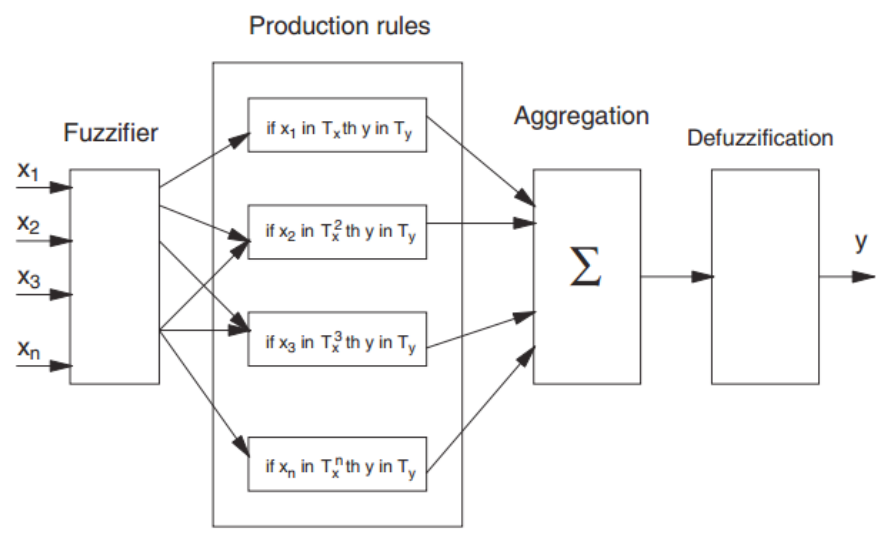

Fig. 3.

Schematic Diagram of a Fuzzy Inference System

\subsubsection{Neuro-Fuzzy Models}

Hybrid models using ANN and Fuzzy set theory were experimented to complement the drawbacks of both the techniques. ANN has a learning capacity and can capture the complex relationship between the variables but needs good amount of data. Fuzzy set theory, on the other hand can capture the linguistic and vague expressions that is more close to human behavior but has no learning ability and also finding out the best suited membership function is very challenging. So on combining both these techniques, can build a very powerful model that has a learning ability as well as can grasp the vagueness involved in human decision making procedure. The various fused NF models that can be used are: Cooperative, Concurrent and Fused Neuro-Fuzzy Systems. In the Cooperative NF model, the ANN decides the membership function or the fuzzy rules to be implemented based on the data and then go to background. In concurrent NF model ANN dynamically assists FIS to set its parameters.

\subsection{Comparison of Various Mode Choice Models}

MNL model has been the most widely used in mode choice analysis and its IIA assumption is misleading as it is not rational. Nested logit model with its tree and branched structure gives some relaxation from the IIA property of MNL but the nested logit structures are either inconsistent with utility maximization principles or are not significantly better than the multinomial logit model. Probit mode choice model which provides greater flexibility, is rarely used in travel demand modeling because these models poses the complexity of introducing several additional parameters in the covariance matrix which require high dimensional integrals which is difficult. Neural Network based mode choice models gives higher accuracy than the logit and probit models because these models are capable in mapping the independent and explained variable but its "black box" image does not help when it comes to easy interpretation of the results. Fuzzy logic based mode choice models employed in modeling does associate closely 
to human linguistic expression but deciding on the best suited membership function is very time taking and tiring process. Table 1 provides basic hypothesis, major constraints, drawbacks and level of accuracy of various mode choice models in the literature.

\section{Table 1}

Comparison of Various Mode Choice Models

\begin{tabular}{|c|c|c|c|c|c|}
\hline $\begin{array}{l}\text { Model } \\
\text { Name }\end{array}$ & Basic Hypothesis & Major constraints & Major Drawbacks & Accuracy & Examples \\
\hline $\begin{array}{l}\text { Logit } \\
\text { model }\end{array}$ & $\begin{array}{l}\text { Extreme value } \\
\text { distribution (Type I } \\
\text { GEV). }\end{array}$ & $\begin{array}{l}\text { Error term should } \\
\text { be identically and } \\
\text { independently } \\
\text { distributed (IID). }\end{array}$ & $\begin{array}{l}\text { Suffers from IIA } \\
\text { assumption. }\end{array}$ & High & $\begin{array}{l}\text { Al Ahmadi (2006); } \\
\text { Mukala and } \\
\text { Chunchu (2011) }\end{array}$ \\
\hline $\begin{array}{l}\text { Probit } \\
\text { model }\end{array}$ & $\begin{array}{l}\text { Normal } \\
\text { distribution. }\end{array}$ & $\begin{array}{l}\text { Error term is non- } \\
\text { identically and } \\
\text { non-independently } \\
\text { distributed. }\end{array}$ & $\begin{array}{l}\text { Difficult interpretation } \\
\text { of results. } \\
\text { Computational } \\
\text { problems. }\end{array}$ & Low & $\begin{array}{l}\text { Bhat and Sardesai } \\
(2006) ; \text { Can (2013) }\end{array}$ \\
\hline $\begin{array}{l}\text { GEV } \\
\text { model }\end{array}$ & $\begin{array}{l}\text { Multivariate } \\
\text { extreme value } \\
\text { distribution. }\end{array}$ & $\begin{array}{l}\text { Independent, but } \\
\text { not identically } \\
\text { distributed error } \\
\text { terms. }\end{array}$ & $\begin{array}{l}\text { Perceived utility of any } \\
\text { alternative should not } \\
\text { exceed an upper bound. }\end{array}$ & Low & Bhat (1995) \\
\hline $\begin{array}{l}\text { ANN } \\
\text { model }\end{array}$ & $\begin{array}{l}\text { Inspired by Human } \\
\text { Neural system. }\end{array}$ & $\begin{array}{l}\text { Performance } \\
\text { depends on } \\
\text { Architecture, Training } \\
\text { and Activation } \\
\text { function. }\end{array}$ & $\begin{array}{l}\text { Difficult to interpret } \\
\text { the result in terms of } \\
\text { natural language. }\end{array}$ & High & $\begin{array}{l}\text { Edara (2003); } \\
\text { Cantarella and De } \\
\text { Luca (2003); Xie } \\
\text { and Parkany (2003); } \\
\text { Ravi Sekhar (1999) }\end{array}$ \\
\hline $\begin{array}{l}\text { Fuzzy } \\
\text { Set } \\
\text { Theory }\end{array}$ & $\begin{array}{l}\text { Based on underlying } \\
\text { assumption of } \\
\text { Commensurability. }\end{array}$ & $\begin{array}{l}\text { Input Values should } \\
\text { be fuzzy. }\end{array}$ & $\begin{array}{l}\text { No learning ability and } \\
\text { difficulty in deciding } \\
\text { Membership function } \\
\text { (Tuning). }\end{array}$ & High & $\begin{array}{l}\text { Deb (1993); Kalic } \\
\text { and Teodorovic } \\
(1999)\end{array}$ \\
\hline $\begin{array}{l}\text { Neuro } \\
\text { Fuzzy } \\
\text { model }\end{array}$ & $\begin{array}{l}\text { ANN and FIS } \\
\text { models complement } \\
\text { each other. }\end{array}$ & $\begin{array}{l}\text { Pre-processing of } \\
\text { input training data is } \\
\text { required. }\end{array}$ & $\begin{array}{l}\text { Lack of common } \\
\text { framework, different } \\
\text { NF models can't be } \\
\text { compared. }\end{array}$ & High & $\begin{array}{l}\text { Rao and Sikdar } \\
\text { (1999); Yaldi et al. } \\
(2010)\end{array}$ \\
\hline
\end{tabular}

\section{Conclusions and Future Ahead}

Review on Mode choice studies carried out in this paper shed light on various aspects of mode choice analysis as a transportation planning process. Mode choice modeling directly deals with the behavioral aspect of human nature thus it needs to closely monitor and understand the factors that affect this decision making procedure. A number of factors come into play and can be broadly classified as characteristics of trip maker characteristics of trip, characteristics of mode as well as the there are many latent factors like comfort and convenience. Modeling of mode choice can be approached in two ways: aggregate modeling and disaggregate modeling. Disaggregate approach is widely used as it can capture the individual characteristics in a much better way compared to aggregate models that depend on zonal characteristics. Disaggregate mode choice models are of three types namely: Logit model, Probit model and General extreme value model. Amongst all the three models, Logit 
models have found the most application in choice models because of simplicity and easy interpretation of results. It also has comparatively reasonable accuracy. Estimation of parameters of model is done by two techniques, Maximum likelihood and Least squares methods. The maximum likelihood is the most common technique used in determining the estimators for simple and nested logit model. The data required for modeling is collected through surveys like household survey, workplace survey, destination survey, and intercept survey. Sampling from the data set is also a crucial step and should be done diligently.

The model specification for mode choice should be done on case specific basis. Suitability of the model selected should be decided first so that the entire process starting right from data collection to analysis and interpretation can be carried out in a very planned and streamlined manner. Indian society due to its disaggregated characteristics needs to be modeled differently than the developed nation where the societies are more of aggregated nature. Due to the complexity involved in the Indian travel characteristics a model highly flexible as well as compatible to handle such heterogeneity should be used. Hybrid models seem to be more promising in this regard. Hybrid mode choice models such as NeuroFuzzy models gives better results than the individual models.

\section{References}

Abdel-Aty, M.; Abdelwahab, H. 2001. Calibration of nested mode choice model for Florida, Final research report, University of central Florida.
Abuhamoud, M.A.A.; Atiq, R.; Rahmat, O.K.; Ismail, A. 2011. Modeling of Transport Mode in Libya: a Binary Logit Model for Government Transportation Encouragement, Australian Journal of Basic and Applied Sciences, 5(5): 1291-1296.

Adler, T.; Rimmer, L.; Carpenter, D. 2002. Use of Internet-Based Household Travel Diary Survey Instrument, Transportation Research Record: Journal of the Transportation Research Board. DOI: http://dx.doi. org/10.3141/1804-18, 1804: 134-143.

Ajzen, I. 1985. From intentions to actions: A theory of planned behavior. In Kuhl, J., Beckman, J. (Eds.), Action-control: From cognition to behavior. Heidelberg, Germany: Springer. 11-39.

Al-Ahmadi, H.M. 2006. Development of Intercity Mode Choice Models for Saudi Arabia, JKAU: Eng.Sci, 17(1): 3-21.

Algers, S.; Bergström, P.; Dahlberg, M.; Dillén, J.L. 1998. Mixed Logit Estimation of the Value of Travel Time, Swedish Institute for Transport and Communications Analysis (SIKA).

Ben-Akiva, M.E.; Lerman, S.R. 1985. Discrete Choice Analysis: Theory and Application to TravelDemand, The MIT Press, Cambridge, Massachusetts, the USA.

Ben-Akiva, M.E.; Morikawa, T. 1990a. Estimation of switching models from revealed preferences and stated intentions, Transportation Research Part A: General. DOI: http://dx.doi.org/10.1016/0191-2607(90)900377, 24(6): 485-495.

Ben-Akiva, M.E.; Morikawa, T. 1990b. Estimation of Travel Demand Models from Multiple Data Sources. In M. Koshi (Ed.), Transportation and Traffic Theory. Oxford: Elsevier Science Ltd. 461-476. 
Bhat, C.R. 1995. A Heteroscedastic Extreme Value Model of Intercity Mode Choice, Transportation Research Part B: Methodological. DOI: http://dx.doi. org/10.1016/0191-2615(95)00015-6, 29(6): 471-483.

Bhat, C.R. 2000. Incorporating Observed and Unobserved Heterogeneity in Urban Work Mode Choice Modeling, Transportation Science. DOI: http://dx.doi. org/10.1287/trsc.34.2.228.12306, 34(2): 228-238.

Bhat, C.R.; Sardesai, R. 2006. The Impact of StopMaking and Travel Time Reliability on Commute Mode Choice, Transportation Research Part B: Methodological. DOI: http://dx.doi.org/10.1016/j.trb.2005.09.008, 40(9): 709-730.

Can, V.V. 2013. Estimation of travel mode choice for domestic tourists to Nha Trang using the multinomial probit model, Transportation Research Part A: Policy and Practice. DOI: http://dx.doi.org/10.1016/j. tra.2013.01.025, 49: 149-159.

Cantarella, G.E.; De Luca, S. 2003. Modeling Transportation Mode Choice through Artificial Neural Networks. In Proceedings of the Fourth International Symposium on Uncertainty Modeling and Analysis. DOI: http://dx.doi.org/10.1109/ISUMA.2003.1236145, 84-90.

Casas, J.; Arce, C. 1999. Trip Reporting in Household Travel Diaries: A Comparison to GPSCollected Data. Presented at the 78th Annual Meeting of the Transportation Research Board, Washington, D.C.

Daganzo, C. 1979. Multinomial Probit: The Theory and its Application to Demand Forecasting, Academic Press, New York.

Deb, S.K. 1993. Fuzzy set approach in mass transit mode choice. In Proceedings of the ISUMA '93, Second International Symposium on Uncertainty Modeling and Analysis. IEEE Computer Press, College Park, Maryland. 262-268.
Dow, J.K.; Endersby, J.W. 2004. Multinomial Probit and Multinomial Logit: A Comparison of Choice Models for Voting Research. Electoral Studies. 23 p.

Edara, P.K. 2003. Mode Choice Modeling Using Artificial Neural Networks, M.S. Thesis, Virginia Polytechnic Institute, Virginia.

Frank, L.; Bradley, M.; Kavage, S.; Chapman, J.; Lawton, T.K. 2008. Urban form, travel time, and cost relationships with tour complexity and mode choice, Transportation. DOI: http://dx.doi.org/10.1007/s11116007-9136-6, 35(1): 37-54.

Ghareib, A.H. 1996. Estimation of Logit and Probit Models in a Mode Choice Situation, Journal of Transportation Engineering. DOI: http://dx.doi. org/10.1061/(ASCE)0733-947X(1996)122:4(282), 122(4): 282-290.

Hess, S. 2005. Advanced discrete choice models with applications to transport demand, Ph.D Thesis, Centre for Transport Studies Imperial College London.

Kalfs, N. 1995. The Effects of Different Data Collection Procedures in Time Use Research. Paper presented at the Transportation Research Board Annual Meeting, Washington, D.C.

Kalic, M.; Teodorovic, D. 1999. Modal Split Modeling Using Fuzzy Logic. In Proceedings of the Conference "Modelling and Management in Transportation", PoznanCracow, Poland. 91-96.

Khan, O. 2007. Modelling Passenger Mode Choice Behavior Using Computer Aided Stated Preference Data, Ph.D Thesis, Queensland University of Technology.

Koppeleman, F.; Bhat, C. 2006. A SelfInstructing Course in Mode Choice Modeling: Multinomial and Nested Logit Models, U.S. Department of Transportation, Federal Transit Administration. 
Koppleman, F.S.; Wen, C-H. 2000. The Paired Combinatorial Logit Model: Properties, Estimation and Application, Transportation Research Part B: Methodological. DOI: http://dx.doi.org/10.1016/S0191-2615(99)000120, 32(2): 75-89.

Lerman, S. 1975. A Disaggregate Behavioral Model of Urban Mobility Decisions, Ph.D. Thesis, Department of Civil Engineering, Massachusetts Institute of Technology, Cambridge, Massachusetts.

Lesley, L. 2009. Generalized Cost and Value of Time As a Method of Patronage Forecasting, Acta Technica Jaurinensis, 2(1): 57-68.

Lisco, T.E. 1967. Value of Commuters time-A Study in Urban Transportation, PhD. Thesis, University of Chicago.

McFadden, D. 1978. Modelling the choice of residential location. In Karlquist A., ed., Spatial Interaction Theory and Planning Models, North Holland, Amsterdam. 75-96.

McFadden, D. 1980. Econometric models for Probabilistic choice among Products, The Journal of Business, 53(3): 13-29.

Mukala, P.K.; Chunchu, M. 2011. Mode choice modelling for intercity transportation in India: A case of Guwahati to five metro cities, International Journal of Earth Sciences and Engineering, 4(6): 364-374.

Ortúzar, J. de D.; Willumsen, L.G. 2002. Modeling Transport, 3rd Edition, JohnWiley \& Sons, Chichester, Sussex, England.

Persson, U.; Nilsson, K.; Hjalte, K.; Norinder, A. 1998. Beräkningav Vägverkets riskvärden. En kombination av "contingent valuation" - skattningar och uppmätta hälsoförluster hos vägtrafikskadade personer behandlade vid fyra sjukhus. The Swedish Institute of Health Economics (IHE), Mimeo.
Pinjari, A.R.; Pendyala, R.M.; Bhat, C.R.; Waddell, P.A. 2007. Modeling residential sorting effects to understand the impact of the built environment on commute mode choice, Transportation. DOI: http://dx.doi.org/10.1007/ s11116-007-9127-7, 34(5): 557-573.

Racca, D.P.; Ratledge, E.C. 2004. Factors That Affect and/or Can Alter Mode Choice, Delaware Transportation Institute and The State of Delaware Department of Transportation, University of Delaware, Newark.

Rao, S.P.V.; Sikdar, P.K. 1999. Calibration of fuzzy functions from revealed preference pattern in urban mode choice. CUPUM '99 Computers in Urban Planning and Urban Management On the edge of the millennium. In Proceedings of the 6th International Conference, Venice.

Ravi Sekhar, Ch. 1999. Mode choice Analysis using Artificial Neural Network, Master Thesis, Indian Institute of Technology, Roorkee.

Seyedabrishami, S.; Shafahi, Y. 2013. A joint model of destination and mode choice for urban trips: a disaggregate approach, Transportation Planning and Technology. DOI: http://dx.doi.org/10.1080/0308106 0.2013.851507, 36(8): 703-721.

Stratham, J.; Dueker, K. 1996. Transit service, parking charges, and mode choice for the journey to work: an analysis of the 1990 NPTS, Journal of Public Transportation, 1(1).

Van Wee, B.; Holwerda, H.; van Baren, R. 2003. Preferences for modes, residential location and travel behaviour: the relevance of land-use impacts on mobility, European Journal of Transport and Infrastructure Research, 2(3-4): 305-315.

Wang, D.; Borgers, A.; Oppewal, H.; Timmermans, H. 2000. A stated choice approach to developing multifaceted models of activity behavior, Transportation Research Part A: Policy and Practice. DOI: http://dx.doi. org/10.1016/S0965-8564(99)00045-2, 34(8): 625-643. 
Wolf, J. 2004. Defining GPS and GPS Capabilities. In Hensher, D., Button, K., Haynes, K., Stopher, P. (editors), Handbook on Transport Geography and Spatial Systems, Elsevier, Handbook No. 5, Chapter 20.

Xie, C.; Lu, J.; Parkany, E. 2003. Work Travel Mode Choice Modeling Using Data Mining: Decision Trees And Neural Networks, Transportation Research Record: Journal of the Transportation Research Board. DOI: http:// dx.doi.org/10.3141/1854-06, 1854: 50-61.

Yaldi, G.; Taylor, A.P.; Yue, W.L. 2010. Examining the Possibility of Fuzzy Set Theory Application in Travel Demand Modelling, Journal of the Eastern Asia Society for Transportation Studies, 8: 579-592.

Yang, L.; Zheng, G.; Zhu, X. 2013. Cross-nested logit model for the joint choice of residential location, travel mode, and departure time, Habitat International. DOI: http://dx.doi.org/10.1016/j.habitatint.2012.06.002, 38: $157-166$.
Ye, X.; Pendyala, R.M.; Gottardi, G. 2007. An exploration of the relationship between mode choice and complexity of trip chaining patterns, Transportation Research Part B: Methodological. DOI: http://dx.doi. org/10.1016/j.trb.2006.03.004, 41: 96-112.

Zadeh, L. 1965. Fuzzy sets, Information and Control, 8: 338-353.

Zenina, N.; Borisov, A. 2011. Transportation Mode Choice Analysis Based on Classification Methods, IT and Management Science, 49: 49-53.

Zhao, F.; Li, M-T.; Chow, L-F.; Gan, A.; Shen, L.D. 2002. FSUTMS Mode Choice Modeling: Factors Affecting Transit Use and Access, National Center for Transit Research, University of South Florida, Tampa, Florida. 